\title{
Influence of adapted hip-hop dancing on quality of life and social participation among children/adolescents with cerebral palsy
}

\author{
Influência da dança hip-hop adaptada na qualidade de vida e na participação social de \\ crianças e adolescentes com paralisia cerebral
}

Joseana Wendling WITHERS', Sandra Baggio MUZZOLON², Marise Bueno ZONTA

\begin{abstract}
To describe the influence of adapted hip-hop dancing on the quality of life (QoL) and biopsychosocial profile of children/adolescents with cerebral palsy (CP). Methods: Pilot study including 18 children/adolescents with CP and Gross Motor Function Classification System levels I and II. Nine participants took part in an adapted hip-hop dance practice (study group; SG), and nine others served as the control group (CG). All participants were assessed with the Pediatric Outcomes Data Collection Instrument and the Child Behavior Checklist at baseline and after at least three months of dance practice and a public performance (SG) or a similar period without intervention (CG). Results: Improvement in QoL was observed in the SG in the domains of transfer and basic mobility ( $p=0.00 *$ ), sporting and physical function $\left(p=0.04^{*}\right)$, and global function and symptoms $\left(p=0.01^{*}\right)$. In the SG, there was a reduction in emotional and behavioral problems and an increase in social competence in the biopsychosocial profile. Greater participation in adapted hip-hop dancing was associated with a greater gain in the transfer and basic mobility domains $\left(p=0.05^{\star}\right)$ of the Pediatric Outcomes Data Collection Instrument and in the activities $\left(p=0.05^{*}\right)$ and social $\left(p=0.04^{\star}\right)$ scales of the Child Behavior Checklist. Conclusions: Children/adolescents with CP participating in adapted hip-hop dance practice showed improvement in QoL and biopsychosocial profile scores.
\end{abstract}

Keywords: Cerebral palsy; dancing, quality of life; social participation; child; adolescent.

\section{RESUMO}

Descrever a influência da dança hip-hop adaptada na qualidade de vida (QV) e no perfil biopsicossocial de crianças/adolescentes com paralisia cerebral (PC). Método: Estudo piloto incluindo 18 crianças/adolescentes com PC, níveis I e II no Sistema de Classificação da Função Motora Grossa. Nove participaram da prática de dança hip-hop adaptada (grupo de estudo; GE) e nove outros compuseram o grupo controle (GC). Os participantes foram avaliados pelo Instrumento Avaliação de Resultados de Reabilitação em Pediatria e pelo Child Behavior Checklist antes e após frequentarem pelo menos três meses de aulas de dança semanais e realizarem uma apresentação ao público (GE) ou período similar sem intervenção (GC). Resultados: A melhora da QV foi observada no GE nos domínios: transferência e mobilidade básica $\left(p=0,00^{*}\right)$, função física e esportiva $\left(p=0,04^{*}\right)$, função global e sintomas $\left(p=0,01^{*}\right)$. Na análise do perfil biopsicossocial, houve redução dos problemas emocionais e comportamentais e aumento da competência social no GE. Maior participação na prática esteve associada a maior ganho nos domínios transferência e mobilidade básica $\left(p=0,05^{*}\right)$ do Instrumento Avaliação de Resultados de Reabilitação em Pediatria e nas escalas de atividades $\left(p=0,05^{\star}\right)$ e sociais $\left(p=0,04^{\star}\right)$ do Child Behavior Checklist. Conclusão: A prática de dança hip-hop adaptada proporcionou melhora nos escores de QV e do perfil biopsicossocial de crianças e adolescentes com PC.

Palavras-chave: Paralisia cerebral; dança; qualidade de vida; participação social, crianças, adolescentes.

Children and adolescents with cerebral palsy (CP) have limitations of posture and movement ${ }^{1}$ and less involvement in the community and in recreational and sports activities ${ }^{2,3}$. They become increasingly sedentary, further reducing social engagement and participation. Although there is a decline in physical aspects with increasing age, this reduction seems to be more related to environmental and family factors, than to the characteristics of the children themselves ${ }^{4,5,6,7,8}$.

\footnotetext{
'Universidade Federal do Paraná, Setor de Ciências da Saúde, Pós-graduação em Saúde da Criança e do Adolescente, Curitiba PR, Brasil; 2Universidade Federal do Paraná, Hospital de Clínicas, Serviço de Psicologia, Curitiba PR, Brasil;

${ }^{3}$ Universidade Federal do Paraná, Hospital de Clínicas, Serviço de Reabilitação, Curitiba PR, Brasil.
}

Joseana Wendling Withers iD https://orcid.org/0000-0002-6540-065X; Sandra Baggio Muzzolon iD https://orcid.org/0000-0003-4992-4055; Marise Bueno Zonta iD https://orcid.org/0000-0003-1652-7723

Correspondence: Joseana Wendling Withers; Rua Floriano Essenfelder, 81, Alto da Glória; 80060-270 Curitiba PR, Brasil; E- mail: joseana.withers@gmail.com Conflict of interest: There is no conflict of interest to declare.

Received 27 August 2018; Received in final form 19 May 2019; Accepted 21 July 2019. 
Community resources and accessibility vary, and often are limited within healthcare systems. The interest in activities and opportunities for therapeutic movement and rehabilitation, such as physical therapy, also decline over time for children with $\mathrm{CP}^{8}$.

In contrast, through social participation, children make contributions to their community, learn about themselves and the expectations of society, and develop the skills necessary to become successful and autonomous in different contexts $^{9}$. The participation of children with physical disabilities in a variety of activities contributes to their perception of a good quality of life (QoL), regardless of their level of physical involvement. A QoL is a broad concept encompassing many components of general health and wellness, such as physical, psychosocial, economic, and cultural factors. The goal should be to include and encourage their participation in all areas of life and in meaningful activities that are adapted and appropriate for their abilities and preferences, as determined by the International Classification of Functionality ${ }^{9,10}$.

Despite opportunities for participation in group activities being even fewer, considering the negative social stereotype associated with these patients and the expectation that they will perform poorly ${ }^{4,6}$, group dance programs have been proposed for children/adolescents with $\mathrm{CP}^{8}$. These programs require the individual to be physically, mentally, emotionally, and socially involved and may improve aspects related to his or her QoL and psychosocial factors ${ }^{11,12,13}$.

Dance classes provide individuals with CP opportunities to explore movement in environments that can address associated impairments. Dance - a creative and expressive art generally involves the performance of movement to music. Incorporating dance as an art form into rehabilitation has the capacity to transcend traditional barriers in therapy that differentially focus on impairments and limitations. Dance enables opportunities for engaging in a social activity, while providing a therapeutic benefit ${ }^{8,12,13}$.

Discrete postures and gestures used in dance constitute the simplest elements of a movement vocabulary that can be used to compose sequences of meaningful movement. These movement sequences may transfer to everyday functional mobility, thereby providing potential rehabilitative benefit. Dance may offer therapeutic benefit to individuals with CP across different therapeutic areas and health and education disciplines, as well as personal artistic development, within multiple contexts for participation; each provides different perspectives and terminologies. Thus, there is a need for a consistent language and framework to consider the mechanisms and processes of dance within rehabilitation, as well as the outcomes that might be facilitated ${ }^{8,12}$.

The aim of this study was to describe the influence of adapted hip-hop dance on the QoL and biopsychosocial profile of children and adolescents with CP.

\section{METHODS}

This was a pilot, prospective, clinical trial, carried out between April, 2007, and December, 2008. The study was approved by the Human Research Ethics Committee of Hospital de Clínicas at Universidade Federal do Paraná, Curitiba, Brazil. All parents/caregivers signed an informed consent form to allow the participation of their children/adolescent in the study.

\section{Participants}

A convenience sample of 18 participants with CP was recruited during appointments at the Pediatric Spasticity Outpatient Clinic at the Neuropediatric Center of Hospital de Clínicas at Universidade Federal do Paraná.

The sample included 18 children and adolescents according to the inclusion criteria: age between 6 and 18 years; motor impairment classified as levels I and II according to the Gross Motor Function Classification System ${ }^{14}$; able to respond appropriately to the questionnaires; have enough cognition to participate in group activities and understand the commands of the dance class; participants in the study group (SG) had to attend classes for at least three months and participate in the artistic presentation. Children and adolescents with associated impairments (vision/hearing) that would compromise participation in dance practice were excluded. Children and adolescents who did not participate in the proposed activity and answered the questionnaires in a similar period were included in the control group (CG). Participants in both groups maintained their attendance in the multidisciplinary interventions offered by the outpatient clinic.

\section{Intervention}

Dance practice in this study was defined as the frequency of attendance at the adapted hip-hop dance classes (Appendix 1), in-home rehearsals, and participation in a dance performance. The dance classes were conducted by a physiotherapist and dancer over 20 months, with one-hour lesson/week, observing the following stages: group warm-up, overall stretching, choreographic composition and improvisation, and relaxing. The intervention was delivered in a location provided by the Association of Parents and Friends of Children with Motor Deficiency, and the space for dance practice featured a hall with a mirror. The patients started the dance classes on different dates, according to their availability, and received CDs with songs for individual home dance rehearsals of the choreography taught in the dance classes. The following week the participants would present the choreography that was practiced at home and note the number of rehearsals practiced and, thus, successively the practices at home were checked every week.

Adherence to the purpose of and affinity with the principles of the offered dance practice enabled the children and 
adolescents to create a dance group named Guerreiros do HipHop (Hip-Hop Warriors), characterized according to hip-hop modality trends. Children/adolescents who took part in the survey participated in a dance performance named Onde está $o$ amor?(Where is the love?) at the Londrina Theater at Memorial de Curitiba (Brazil; https://youtu.be/37qu3swb6lc; http://institutoguerreiros.com.br/site/onde-esta-o-amor/) (Figure).

\section{Outcome measures}

Demographic and socioeconomic data at the initial assessment (moment 1 - M1), topographic classification, Gross Motor Function Classification System level, interval between questionnaires, total duration of dance practice (in months), number of attended classes, and total number of home rehearsals were considered. The education level was based on the Brazilian model: primary school I (Grades 1-4), primary school II (Grades 5-8), and high school.

To measure the impact of adapted hip-hop dancing on the QoL, undergraduate students, blinded to group allocation, explained to the parents about the version for parents of the Pediatric Outcomes Data Collection Instrument ${ }^{15}$ for individuals under the age of 19 years. The questionnaires are self-applicable and comprise 108 objective questions distributed in six domains: upper extremity and physical function, transfer and basic mobility, sporting and physical function, pain and comfort, happiness, and global function and symptoms. The undergraduate students were available to answer any questions.
To measure the impact of adapted hip-hop dancing on the participants' biopsychosocial profile, the Child Behavior Checklist for ages 6-18 years ${ }^{16}$ was completed by a parent or caregiver of the participant. The first part of the Child Behavior Checklist assesses social competence related to activities, sociability, and scholarship, and the second part evaluates the presence of emotional and behavior problems. The undergraduate students who explained to the parents about the completion and were available to answer any questions also delivered this questionnaire.

The baseline moment, M1, defined the assessment with the questionnaires (Pediatric Outcomes Data Collection Instrument and Child Behavior Checklist) before the dance practice, while M2 defined the assessments of the SG after the dance practice and the $\mathrm{CG}$ after a similar period without dance practice.

Four scores were attributed, taking into account four subjective aspects of dance practice performance in the SG: concentration, self-confidence, aptitude, and participation. The score was attributed only once, at the last dance practice, and was based on the instructor's perspective:

- 1-4: Very unfocused to very focused;

-1-4: Substantial lack of self-confidence to increased self-confidence;

-1-3: Little aptitude to substantial aptitude;

-1-3: Little participation to substantial participation.

These scores were then correlated with other study variables.
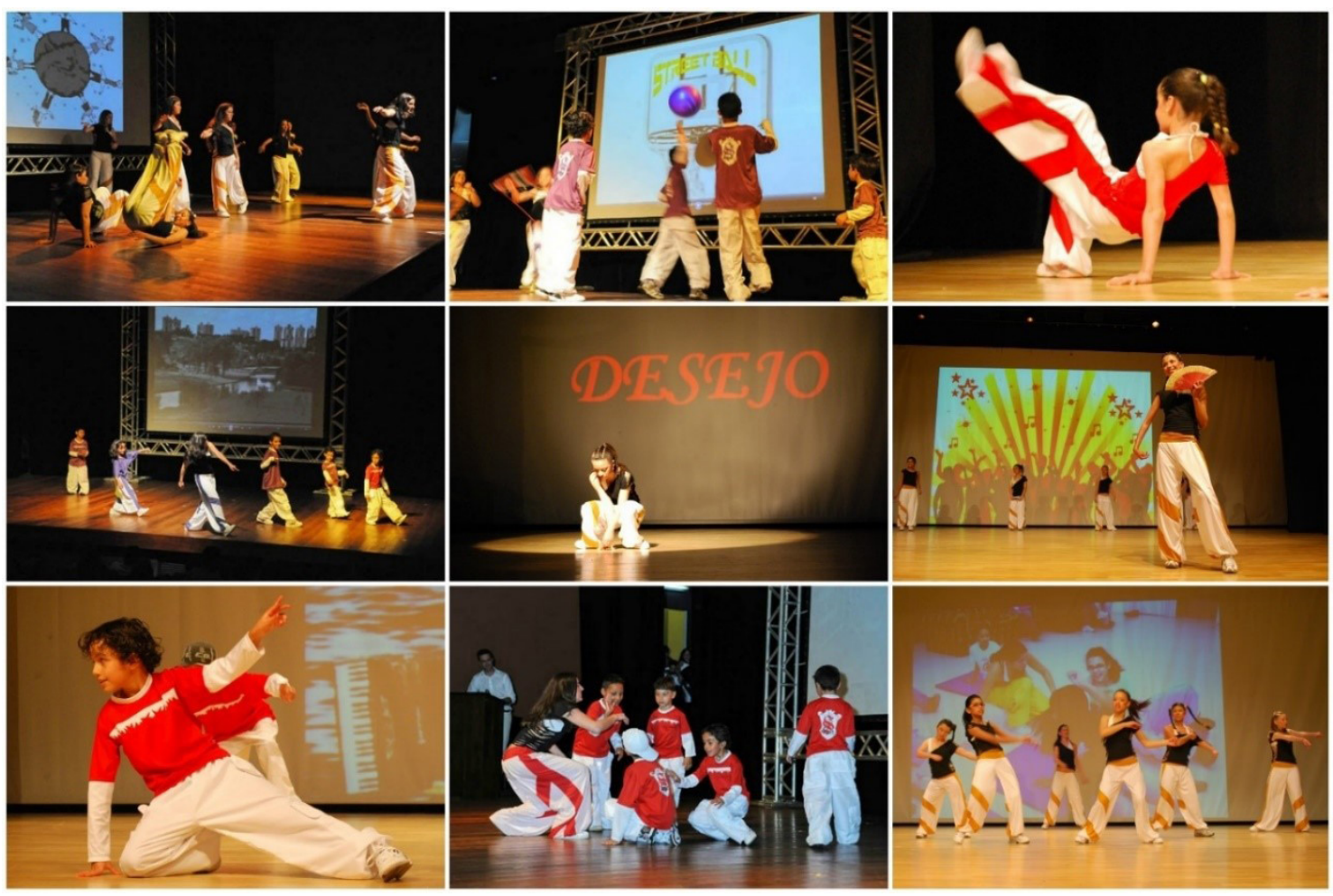

Curitiba, PR, Brazil. 11/5/2008.

Figure. Guerreiros do Hip-Hop (Hip-Hop Warriors) Group Dance Show "Where's the love?" 


\section{Statistical analysis}

The Mann-Whitney nonparametric test was used for group comparison, and the Wilcoxon nonparametric test was adopted to compare the assessment moments (M1 and M2) in the groups. Spearman's correlation coefficient estimated the correlation among ordinal or quantitative variables. The analysis included the variation between the values obtained at M1 and M2 of the items in the Pediatric Outcomes Data Collection Instrument and Child Behavior Checklist questionnaires in the SG. Values are represented as mean and standard deviation (SD) and $\mathrm{p}<0.05$ indicated statistical significance. The data were analyzed with Statistica, v.8.0.

\section{RESULTS}

Table 1 provides detailed data on all $18 \mathrm{CP}$ participants.

Each group comprised nine participants, with five girls in each group. The mean age was $12.9( \pm 4.1)$ years in the $S G$ and $10.0( \pm 2.5)$ years in the CG. The groups were homogeneous in relation to demographics and topographic classification. The majority of the participants in the SG were classified as Gross Motor Function Classification System level I ( $p=0.049$ ).

The mean period between questionnaire applications was $7.85( \pm 3.5)$ months in the SG and $11.9( \pm 3.2)$ months in the $\mathrm{CG}$, with significant differences in the Pediatric Outcomes Data Collection Instrument $(p=0.008)$ and Child Behavior Checklist ( $\mathrm{p}=0.04)$. In the $\mathrm{SG}$, the mean number of classes attended between questionnaire applications was $20.8( \pm 7.4)$
(Table 1). The number of home rehearsals varied from 0 to 7 , with a mean of three per week.

\section{Comparison of M1 and M2 within each group}

The differences in the QoL and biopsychosocial profile were considered for each group separately, by comparing M1 and M2 within each group using the Wilcoxon nonparametric test. No significant difference in QoL in the Pediatric Outcomes Data Collection Instrument dimensions was observed within each group. At M1 and M2, the mean score for all five dimensions measuring QoL in the SG was within expectations and comparable to that found in typical children.

In the CG, the mean score in the dimension of sporting and physical function was below expectations at both moments, and so was the mean score for pain and comfort and global function and symptoms at M2.

Considering the participants' biopsychosocial profile, there were significant improvements at M2 in 11 Child Behavior Checklist scales in the SG, while only three scales of this checklist improved in the CG. At M1, the mean Child Behavior Checklist score for the scale total competence classified the SG as "borderline" and the CG as "clinical". At M2, the SG was rated "normal" and the CG was rated "borderline". Both groups were considered borderline for the scale of internalizing problems at M1, but became normal at M2 (Table 2).

\section{Comparison of M1 and M2 between groups and variations}

The Mann-Whitney nonparametric test was used for this comparison. The QoL assessed by the Pediatric

Table 1. Characteristics of the children and adolescents in the study group and control group.

\begin{tabular}{|c|c|c|}
\hline Variable & Study group & Control group \\
\hline \multicolumn{3}{|l|}{ Sex } \\
\hline Male & $55.6 \%$ & $55.6 \%$ \\
\hline Female & $44.4 \%$ & $44.4 \%$ \\
\hline \multicolumn{3}{|l|}{ Race } \\
\hline White & $44.4 \%$ & $44.4 \%$ \\
\hline Black & $55.6 \%$ & $55.6 \%$ \\
\hline \multicolumn{3}{|l|}{ Education level } \\
\hline Primary school I & $50.0 \%$ & $56.6 \%$ \\
\hline Primary school II & $30.0 \%$ & $44.4 \%$ \\
\hline High school & $20.0 \%$ & $0.0 \%$ \\
\hline \multicolumn{3}{|l|}{ Gross Motor Function Classification System } \\
\hline Level I & $88.9 \%$ & $33.3 \%$ \\
\hline Level II & $11.1 \%$ & $66.7 \%$ \\
\hline \multicolumn{3}{|l|}{ Spasticity topography } \\
\hline Hemiplegia & $88.9 \%$ & $55.6 \%$ \\
\hline Diplegia & $11.1 \%$ & $44.4 \%$ \\
\hline Age - years - Mean (SD) & $12.9(4.1)$ & $10.0(2.5)$ \\
\hline Income - (in Brazilian real) Mean (SD) & $333.3(207.4)$ & $203.9(90.7)$ \\
\hline Number of dance classes practiced - Mean (SD) & $20.8(7.4)$ & - \\
\hline Months of dance practiced - Mean (SD) & $7.85(3.5)$ & - \\
\hline Period between questionnaires - Mean (SD) & $7.85(3.5)$ & $11.9(3.2)$ \\
\hline
\end{tabular}


Outcomes Data Collection Instrument at M1 showed that the transfer and basic mobility scores in both groups were similar and within the expected mean: SG: 95.2 (5.8) / CG: 89.3 (5.9). The mean scores at M2 increased in the SG, with a mean value of $96.1( \pm 5.3)$ and decreased in the CG, with corresponding values of $81.9( \pm 18.7)$ and $p=0.00 *$. For the global function and symptoms domain, both groups had similar mean scores at M1: SG: $87.4( \pm 7.5) / \mathrm{CG}: 82.7( \pm$ 9.2) whereas at M2, the mean scores increased in the SG: $89.2( \pm 7.7)$ but decreased in the CG: $78.9( \pm 8.2), p=0.01 *$ For the sporting and physical function domain, the mean scores at M1 were considered to be within the expected mean in the SG: $86.2( \pm 6.8)$ but below that in the CG: $73.8( \pm 13.8), p=0.04 *$. At M2, the mean scores remained roughly the same in the SG: $86.6( \pm 6.7)$ but decreased in the CG: $68.9( \pm 11.7), p=0.00 *$, increasing the difference between the groups.

In relation to the biopsychosocial profile social competence scales, both groups were similar at M1 on the Child Behavior Checklist item social: mean SG: 43.8 ( \pm 4.9); CG: 39.3 ( \pm 11.2 ). At M2, the mean score increased in the SG: 48.9 $( \pm 7.6)$ and decreased in the CG: $35.6( \pm 5.1)$, rendering both results significantly different $(p=0,00 *)$. For the total competence scale, the groups differed $(p=0.04)$ at $\mathrm{M} 1$, with higher mean scores in the SG: $39.6( \pm 5.9)$ versus $31.8( \pm 6.3)$ in the CG. At M2, the mean scores increased in both groups, but the increase was more substantial in the SG: $44.1( \pm 10)$ than the CG: $34( \pm 4.0)$, increasing the difference between both groups $(\mathrm{p}=0.10 \%)$.

Comparing the variations in Child Behavior Checklist scores at M2 and M1 in each group, we observed that the symptoms reduced in the SG for anxious/depressed ( $\mathrm{p}=$ $\left.0.03^{*}\right)$, aggressive behavior ( $\left.\mathrm{p}=0.01^{*}\right)$, externalizing problems $\left(\mathrm{p}=0.00^{*}\right)$, and total problems $\left(\mathrm{p}=0.01^{*}\right)$, while in the
CG these scores remained the same or decreased slightly. Regarding the scales for anxiety problems $(p=0.03 \%)$ and somatic complaints $\left(\mathrm{p}=0.03^{*}\right)$, both groups were similar at M1, but at M2 the scores decreased significantly in both groups, more substantially in the SG (Table 3).

\section{Correlation between quantitative factors}

Spearman's correlation coefficient (r) was used to correlate the quantitative results of the previous analyses with the scores attributed to the participants and their demographic and clinical data (Table 4).

According to the Hopkins classification (2000), the highest gain in transfer and basic mobility of the Pediatric Outcomes Data Collection Instrument presented a very strong correlation with the greater number of classes attended $\left(r=0.72, p=0.03^{*}\right)$ and strong with a longer period of dance practices in months $(r=0.67, p$ $\left.=0.05^{*}\right)$. A longer period of dance practices also showed a very strong correlation with a higher gain in the Child Behavior Checklist scales activities $\left(r=0.76, p=0.05^{*}\right)$ and social competence $(\mathrm{r}=0.80, \mathrm{p}=0.04 \%)$. A reduction of symptoms of internalizing problems $(r=0.71, p=0.03 *)$ and externalizing problems $(\mathrm{r}=0.74, \mathrm{p}=0.02 *)$ showed a very strong correlation with lower age, and total problems $\left(r=0.65, p=0.06^{*}\right)$ showed a strong correlation with lower age (Table 4).

A reduction of symptoms in the syndromes of withdrawn/depression and affective problems correlated with better scores in concentration, security, aptitude, participation, and more time in home practice (all $\mathrm{p}<0.05^{*}$ ). Greater participation showed a strong correlation with a higher gain in social competence $\left(\mathrm{r}=0.67, \mathrm{p}=0.05^{*}\right)$, while the number of home rehearsals showed a strong correlation with a reduction in anxiety problems $\left(\mathrm{r}=0.81, \mathrm{p}=0.05^{*}\right)$ (Table 4).

Table 2. Child Behavior Checklist for ages 6-18 years scales with significant differences in mean values between moments 1 (M1) and 2 (M2) in the study and control groups*.

\begin{tabular}{|c|c|c|c|}
\hline Child behavichecklist scales & Mean of M1 & Mean of M2 & $\mathrm{p}$-value \\
\hline \multicolumn{4}{|l|}{ Study group } \\
\hline Anxious/depressed & $59.1(6.3)$ & $53.7(5.7)$ & $0.03 *$ \\
\hline Somatic complaints & $58.1(7.2)$ & $53.1(2.8)$ & $0.03 *$ \\
\hline Social problems & $63.6(8.2)$ & $57.9(8.3)$ & $0.04^{\star}$ \\
\hline Thought problems & $56.7(8.0)$ & $52.0(3.3)$ & $0.03 *$ \\
\hline Aggressive behavior & $60.1(9.4)$ & $54.6(4.5)$ & $0.02 *$ \\
\hline Internalizing problems & $60.7(8.2)$ & $52.8(9.9)$ & $0.02^{\star}$ \\
\hline Externalizing problems & $57.4(8.6)$ & $51.6(6.9)$ & $0.02 *$ \\
\hline Total problems & $60.3(9.3)$ & $52.1(9.4)$ & $0.01 *$ \\
\hline Affective problems & $63.6(8.0)$ & $57.3(7.3)$ & $0.02 *$ \\
\hline Anxiety problems & $58.4(4.4)$ & $52.3(3.1)$ & $0.02 *$ \\
\hline Oppositional defiant problems & $53.9(6.4)$ & $53.8(3.3)$ & $0.02^{\star}$ \\
\hline \multicolumn{4}{|l|}{ Control group } \\
\hline Somatic complaints & $63.3(5.1)$ & $59.9(7.8)$ & $0.02 *$ \\
\hline Somatic problems & $62.0(6.0)$ & $58.2(5.0)$ & $0.04^{\star}$ \\
\hline Attention deficit/hyperactivity problems & $58.3(6.9)$ & $55.0(4.9)$ & $0.02 *$ \\
\hline
\end{tabular}


Table 3. Comparison between the study and control groups in relation to the scores obtained at moments 1 and 2 (M1 and M2, respectively) and the variation between the scores related to the Child Behavior Checklist for ages 6-18 years syndromes*.

\begin{tabular}{|c|c|c|c|c|c|}
\hline Variable & M & Group & $\mathrm{N}$ & Mean (SD) & $p$-value \\
\hline \multirow{6}{*}{ Anxious/Depressed } & \multirow{2}{*}{ M1 } & C & 9 & $59.1(6.7)$ & \multirow{3}{*}{0.93} \\
\hline & & $S$ & 9 & $59.1(6.3)$ & \\
\hline & \multirow{2}{*}{ M2 } & C & 9 & $58.9(7.8)$ & \\
\hline & & S & 9 & $53.7(5.7)$ & \multirow[t]{2}{*}{0.06} \\
\hline & \multirow{2}{*}{ Variation } & C & 9 & $-0.2(6.4)$ & \\
\hline & & $S$ & 9 & $-5.4(5.6)$ & $0.03 *$ \\
\hline \multirow{6}{*}{ Somatic Complaints } & \multirow{2}{*}{ M1 } & C & 9 & $63.3(5.1)$ & \multirow{3}{*}{0.06} \\
\hline & & S & 9 & $58.1(7.2)$ & \\
\hline & \multirow{2}{*}{ M2 } & C & 9 & $59.9(5.9)$ & \\
\hline & & $S$ & 9 & $53.1(2.8)$ & \multirow[t]{2}{*}{$0.02 *$} \\
\hline & \multirow{2}{*}{ Variation } & C & 9 & $-3.4(3.0)$ & \\
\hline & & $S$ & 9 & $-5.0(5.7)$ & \multirow[t]{2}{*}{0.49} \\
\hline \multirow{6}{*}{ Aggressive Behavior } & \multirow{2}{*}{ M1 } & C & 9 & $55.1(4.5)$ & \\
\hline & & S & 9 & $60.1(9.4)$ & \multirow[t]{2}{*}{0.19} \\
\hline & \multirow{2}{*}{ M2 } & C & 9 & $56.4(6.5)$ & \\
\hline & & $S$ & 9 & $54.6(4.5)$ & \multirow[t]{2}{*}{0.67} \\
\hline & \multirow{2}{*}{ Variation } & C & 9 & $1.3(2.9)$ & \\
\hline & & $S$ & 9 & $-5.6(7.5)$ & $0.01 *$ \\
\hline \multirow{6}{*}{ Externalizing Problems } & \multirow{2}{*}{ M1 } & C & 9 & $53.2(8.6)$ & \multirow{3}{*}{0.55} \\
\hline & & $S$ & 9 & $57.4(8.6)$ & \\
\hline & \multirow{2}{*}{ M2 } & C & 9 & $55.6(7.2)$ & \\
\hline & & $S$ & 9 & $51.6(6.9)$ & \multirow[t]{2}{*}{0.44} \\
\hline & \multirow{2}{*}{ Variation } & C & 9 & $2.3(3.8)$ & \\
\hline & & $S$ & 9 & $-5.9(5.3)$ & \multirow[t]{2}{*}{$0.00 *$} \\
\hline \multirow{6}{*}{ Total Problems } & \multirow{2}{*}{ M1 } & C & 9 & $58.8(8.0)$ & \\
\hline & & $S$ & 9 & $60.3(9.3)$ & 0.80 \\
\hline & 12 & C & 9 & $58.1(7.1)$ & \\
\hline & $\mathrm{IVI} /$ & $S$ & 9 & $52.1(9.4)$ & 0.26 \\
\hline & Variation & C & 9 & $-0.7(2.5)$ & \\
\hline & variation & S & 9 & $-8.2(6.6)$ & $0.01 \star$ \\
\hline & $M 1$ & C & 9 & $57.9(5.7)$ & \\
\hline & $\mid M I I$ & $S$ & 9 & $58.4(4.4)$ & 0.80 \\
\hline Anvinty Problome & M? & C & 9 & $56.8(4.7)$ & \\
\hline Anxiety Problems & $\mathrm{MIL}$ & $S$ & 9 & $52.3(3.1)$ & $0.03 *$ \\
\hline & Variation & C & 9 & $-1.1(5.5)$ & \\
\hline & variation & $S$ & 9 & $-6.1(5.5)$ & 0.11 \\
\hline
\end{tabular}

N: number of participants; SD: standard deviation; C: control group; S: study group.

Observation: Variation refers to the variation between scores at M1 and M2.

*Mann-Whitney test.

No sex influence was observed on the items assessed by the Pediatric Outcomes Data Collection Instrument and Child Behavior Checklist.

\section{DISCUSSION}

The present study assessed the impact of the practice of adapted hip-hop dancing by children/adolescents with $\mathrm{CP}$ and found an effective improvement in QoL in the SG, particularly in the transfer and basic mobility, sporting and physical function, and global function and symptoms domains.
There was also a positive impact of adapted hip-hop dance practice on the participants' biopsychosocial profile through a reduction of symptoms related to the scales of emotional and behavior problems, and an increase of symptoms related to social competence. In addition to promoting psychomotor and physical work and influencing functionality, this pleasant activity is an option for seeking consistent alternatives for better social integration and QoL of children/ adolescents with $\mathrm{CP}^{9,17}$.

Although the QoL indexes are similar for children/adolescents classified with Gross Motor Function Classification System levels I and $\mathrm{II}^{18}$, there was greater interest in adapted 
Table 4. Correlation between score variations obtained with the Child Behavior Checklist for ages 6-18 years and Pediatric Outcomes Data Collection Instrument dimensions, and quantitative and qualitative variables attributed to dance practice.

\begin{tabular}{|c|c|c|c|}
\hline Correlated variables & $\begin{array}{l}\text { Spearman's } \\
\text { coefficient }\end{array}$ & Correlation Hopkins (2000) & $p$-value \\
\hline Period (months) X transfer and basic mobility var & 0.67 & Strong & $0.05^{\star}$ \\
\hline$N$ (classes) X transfer and basic mobility var & 0.72 & Very strong & $0.03^{*}$ \\
\hline Age X Internalizing Problems var & 0.71 & Very strong & $0.03 *$ \\
\hline Age X Externalizing Problems var & 0.74 & Very strong & $0.02 *$ \\
\hline Age X Total Problems var & 0.65 & Strong & 0.06 \\
\hline Period (months) X Activities var & 0.76 & Very strong & $0.05^{\star}$ \\
\hline Period (months) X Social Competence var & 0.80 & Very strong & $0.04^{*}$ \\
\hline Scholarship X Total Problems var & 0.69 & Strong & $0.04^{*}$ \\
\hline Concentration X Withdrawn/Depression var & -0.75 & Very strong & $0.02 *$ \\
\hline Concentration X Affective Problems var & -0.73 & Very strong & $0.03 *$ \\
\hline Security X Withdrawn/Depression var & -0.91 & Extremely strong & $0.00 *$ \\
\hline Security X Affective Problems var & -0.88 & Very strong & $0.00 *$ \\
\hline Aptitude XWithdrawn/Depression var & -0.89 & Very strong & $0.00 *$ \\
\hline Aptitude X Affective Problems var & -0.79 & Very strong & $0.01 *$ \\
\hline Participation X Withdrawn/Depression var & -0.74 & Very strong & $0.02 *$ \\
\hline Participation XAffective Problems var & -0.69 & Strong & $0.04^{\star}$ \\
\hline Participation X Social Competence var & 0.67 & Strong & $0.05^{\star}$ \\
\hline Home Practice X Withdrawn/Depression var & -0.76 & Very strong & $0.02 *$ \\
\hline Home Practice X Affective Problems var & -0.90 & Extremely strong & $0.00 *$ \\
\hline Home Practice X Anxiety Problems var & -0.81 & Very strong & $0.01 *$ \\
\hline
\end{tabular}

var: variation between scores obtained at moments 1 and 2 (M1 and M2, respectively) of the study. Period (months) refers to the period of practice in months; $\mathrm{N}$ (Classes) refers to the number of attended classes; home practice refers to dance practice at home.

*Spearman's correlation coefficient.

hip-hop dancing by participants with level I gross motor functions. Functional limitations were probably a barrier to participation for children with greater impairment. Functional limitation has been identified as the main barrier to this type of program, followed by cost and accessibility difficulties ${ }^{4}$. The mean age of the participants in both groups corresponded to the beginning of the stabilization phase of gross motor function for Gross Motor Function Classification System levels I and II ${ }^{14}$.

The positive impact of adapted hip-hop dancing on the QoL and biopsychosocial profile observed in this study is aligned with the recommendations by the World Health Organization ${ }^{10}$ and suggests that adapted hip-hop dancing may be a consistent physical and social activity to be offered to children/adolescents with CP. Our motivation to investigate the impact of adapted hip-hop dancing in this study was based on our awareness of the inconsistent results derived from drug and motor control interventions in the QoL of individuals with $\mathrm{CP}^{19}$. These interventions have been poorly associated with improvements in these individuals' functional level and performance in activities ${ }^{20,21}$. Dance has been reported by LopezOrtiz et al..$^{12}$ as improving balance and by Teixeira-Machado et al. ${ }^{11}$ as having a positive effect on functionality and social activities related to psychosocial adjustments in young patients with $\mathrm{CP}$, but none of these authors has specifically evaluated the QoL of the participants in their studies ${ }^{11,12}$.

The Pediatric Outcomes Data Collection Instrument is considered a sensitive tool to detect changes over time ${ }^{15}$.
Indicators of this instrument may be used to monitor stabilization or deterioration or improvement in clinical evolution, and are valid for assessing several interventions ${ }^{22}$. Even though it was an extensive instrument, there was no difficulty in the fulfilling and the understanding thereof by the parents.

Herman $^{23}$ has pointed out the main attributes of dance skill training from the neurophysiological point of view and mapped to the most salient items of the International Classification of Functionality ${ }^{23}$. The training of the seven dance skills in relation to the motor control were correlated with the 40 items of the International Classification of Functionality Body Structures and Functions and with 38 items of Activities and Participation. The same skills reported were also observed during the practice of adapted hip-hop dancing in the present study: control of equilibrium and posture; control of complex movements; timing and synchronization in dance performance; motor learning and memory in dance perception and performance; visuomotor and spatial transformations and mental imagery; neural substrates for observation of motor actions and esthetics and expression.

The similarity in QoL dimensions assessed with the Pediatric Outcomes Data Collection Instrument in the SG before and after the dance practice, added to findings that the mean score in the SG was aligned with expectations at M1. This corroborates the findings that the QoL of children/ adolescent with $\mathrm{CP}$ is, on average, similar to that of individuals in the general population ${ }^{21}$. 
Even though there was no significant change in the QoL of the participants in both groups, the scores that we observed were below expectation in the CG for sporting and physical function at both moments, and for pain and comfort and global function and symptoms at M2, which decreased. This is probably due to a larger number of participants with Gross Motor Function Classification level II, who present with greater physical disability and pain ${ }^{14}$. In contrast, the fact that the SG was within expectations shows that dance practice can help maintain physical and global functions and prevent pain/discomfort, which are factors that affect the QoL in children with disabilities ${ }^{20,21}$.

In the SG, the correlation between global function and symptoms and transfer and basic mobility improvement with the number of classes attended and the time of dance practice can be attributed to the physical work performed in dance practice. Studies have shown that physical/motor aspects such as flexibility, coordination, and balance in young individuals with $\mathrm{CP}$ benefit from dance practice and are important to prevent inactivity leading to loss of strength, endurance, and mobility in these individuals ${ }^{11,12}$. While dancers seek to optimize their performances, the vast repertoire of styles and body techniques that comprise hip-hop ${ }^{24}$ serve as a motivation, which is recognized as key to neuroplasticity $^{25}$ while stimulating motor learning ${ }^{26}$.

Well-marked rhythmic beats require the execution of defined body movements, usually augmenting or isolating some body parts. This demands from the dancer body awareness and trunk mobility ${ }^{24}$, preventing complications and deterioration of his or her health status ${ }^{27}$. Rhythmic alternation suggests that movements are executed repetitively, which benefits motor learning and reduces spasticity ${ }^{26}$. The movements of the trunk and lower and upper limbs can be trained separately to be executed simultaneously and continuously, in a coordinated way and synchronized with the rhythm ${ }^{24}$.

The training promotes dissociation of the pelvic and scapular waists, which is necessary to reduce fixed postures caused by spasticity ${ }^{26}$. The movements carried out on the floor stimulate the weight transfer to hands and feet for body support $^{24}$, necessary for appropriate bone development, neuromuscular stimulation, and muscle strengthening, as well as to reduce neglect of the affected limbs ${ }^{26}$. Recommended shoes for this dance are sneakers with flat soles, which enable orthosis during the activity. The movements can be selected and adjusted to promote heel support and avoid plantar flexion.

Regarding the biopsychosocial profile, there were significant changes in the SG related to the improvement of 11 Child Behavior Checklist scales, while only three of these scales improved in the CG. Even though the mean time between the applications of the questionnaires was longer in the CG, better results were obtained in a shorter time by the SG.

The improvement of the SG in relation to the CG in the syndromes of anxiety/depression, somatic complaints, aggressive behavior, anxiety problems, externalizing problems and total problems, corroborates studies that have observed that the experience of group dance awakens healthy emotional states by allowing the manifestation of feelings during practice. At the same time, the group experience requires suitability and discipline, with a consequent sense of satisfaction and self-value ${ }^{11,12,28,29,30}$.

In this pilot study, the classification of the scale internalizing problems changed from borderline to normal in the SG after dance practice, while the CG remained borderline, a result that corroborates the significant improvement in the scores and classification of children undergoing art therapy ${ }^{31}$.

The increase in social scale scores in the SG, compared with their decrease in the $\mathrm{CG}$, shows that the interpersonal relationships experienced in dance practice were determinant for the positive results and corroborate studies that observed increased socialization in individuals exposed to therapeutic dance ${ }^{11,28}$. The correlation between increased social scale scores in the SG with the longest participation time in months and in the number of classes, corroborates a study that observed that the intensity of participation in physical activities correlates with physical and psychosocial well-being 9 . According to the authors, effective social participation contributes to mental and physical health and social relations, and may improve the QoL of disabled individuals $^{9,17}$. In general, the QoL of children/adolescents with CP is not considered inferior to that of the general population, except in the social domain and especially in adolescents; this demonstrates the importance of encouraging participation in group activities ${ }^{19,20,21}$. The development of friendship is considered a relevant and preventive social welfare aspect in the passage from childhood to adolescence ${ }^{17,21}$, and has also been observed with dance practice.

The fact that younger children presented better results in the Child Behavior Checklist scales of internalizing problems, outsourcing problems, and total problems may be explained by the fact that these children are more susceptible to approaches aiming at modifying their biopsychosocial profile. Home rehearsals turned out to be a tool for those with higher scores in the anxiety problems scale, as they dedicated more time to this activity.

Even though there was no relationship between the number of classes attended and the positive changes obtained in the Child Behavior Checklist syndromes, a minimum frequency rate in the adapted hip-hop dance classes was noted to be enough for the participants to experience a feeling of belonging. Although the participants showed a difference in physical, emotional, and artistic abilities, class participation, group formation, and artistic performance were common experiences for all members, and similar to those experienced by environmental artists.

Granier $^{28}$ highlighted that successful work with art therapy may lead to performances, exhibitions, and life projection for some individuals. In the present study, the dance 
performance was an incentive for better individual performance. Even children with lower aptitude were interested in taking part in the performance, which corroborates Granier's observation regarding the benefits of art therapy, both as an artistic investment and a participatory group network $\operatorname{link}^{28}$. The participants in the present study interacted effectively in a pleasant and motivating activity and experienced social participation in a new context, mentioned by some authors as an important and necessary factor for a better QoL among individuals with disabilities ${ }^{9,17}$.

The results of this pilot study are limited, considering that an ideal design for the study would have included randomization and blinding, with greater control over the inclusion criteria, methods for group allocation, simultaneous initiation of the study and application of the measuring instruments for all participants, and assessment of baseline characteristics of the participants in each group. Ideally, the SG and CG samples should be homogeneous in regards to functional level. Currently, recommended instruments to measure QoL place less emphasis on physical condition. Considering that the Pediatric Outcomes Data Collection Instrument assessed the dimensions of pain, comfort, and happiness and that the Child Behavior Checklist encompassed behavioral, emotional, and social aspects, determinant factors were clearly evaluated ${ }^{20}$. Even so, we could appreciate the benefits of adapted hip-hop dancing on the QoL and the biopsychosocial profile, which have encouraged us to continue these activities until today (Brazil, https://youtu.be/uugxI_tUyB8).
Based on the results shown, it was possible to conclude that the influence of adapted hip-hop dancing was positive in the physical, emotional and social aspects analyzed, mainly in the scores in transfer and basic mobility, physical and sports function, and global function and symptoms of the Pediatric Outcomes Data Collection Instrument; and in the items of social competence and behavioral and emotional problems items of the Child Behavior Checklist. The positive results of this research suggest that more studies should be carried out to safely and efficiently expand this practice, so it may be performed more frequently, to become a great ally to the well-being of children and adolescents with CP.

\section{ACKNOWLEDGMENTS}

The authors thank all children/adolescents who have taken part in this research, their families for their commitment, and all volunteers who contributed to this study. We are especially grateful to Dr. Lúcia Helena Coutinho dos Santos, deceased on October 31st, 2015. Dr. Santos, a beloved neuropediatrician and associate professor at Universidade Federal do Paraná, had mentored this project and the Master's degree thesis associated with it. Her knowledge and unconditional encouragement enabled the practical evidence derived from this study to be translated into science to offer a new reality for children and adolescents with cerebral palsy. We also thank Katia Suzana Wendling, Milena Braga-Basaria, and Veronica Doetzer for the linguistic revision of the manuscript.

\section{References}

1. Rosenbaum P, Paneth N, Leviton A, Goldstein M, Bax M, Damiano D, et al. A report: the definition and classification of cerebral palsy April 2006. Dev Med Child Neurol Suppl. 2007 Feb;109 Suppl:8-14.

2. Colver AF, Dickinson HO. Study protocol: determinants of participation and quality of life of adolescents with cerebral palsy: a longitudinal study (SPARCLE2). BMC Public Health. 2010 May;10(1):280. https://doi.org/10.1186/1471-2458-10-280

3. Dickinson HO, Rapp M, Arnaud C, Carlsson M, Colver AF, Fauconnier J, et al. Predictors of drop-out in a multi-centre longitudinal study of participation and quality of life of children with cerebral palsy. BMC Res Notes. 2012 Jun;5(1):300. https://doi.org/10.1186/1756-0500-5-300

4. Murphy NA, Carbone PS. Promoting the participation of children with disabilities in sports, recreation, and physical activities. Pediatrics. 2008 May;121(5):1057-61. https://doi.org/10.1542/peds.2008-0566

5. Colver A. Quality of life and participation. Dev Med Child Neurol. 2009 Aug;51(8):656-9. https://doi.org/10.1111/j.1469-8749.2009.03321.x

6. Michelsen SI, Flachs EM, Damsgaard MT, Parkes J, Parkinson K, Rapp M, et al. European study of frequency of participation of adolescents with and without cerebral palsy. Eur J Paediatr Neurol. 2014 May;18(3):282-94. https://doi.org/10.1016/j.ejpn.2013.12.003

7. Michelsen SI, Flachs EM, Uldall P, Eriksen EL, McManus V, Parkes J, et al. Frequency of participation of 8-12-year-old children with cerebral palsy: a multi-centre cross-sectional European study. Eur J Paediatr Neurol. 2009 Mar;13(2):165-77. https://doi.org/10.1016/j.ejpn.2008.03.005
8. López-Ortiz C, Gaebler-Spira DJ, Mckeeman SN, Mcnish RN, Green D, et al. Dance and rehabilitation in cerebral palsy: a systematic search and review. Dev Med Child Neurol. 2019 Apr;61(4):393-8. https://doi.org/10.1111/dmcn.14064

9. Shikako-Thomas K, Dahan-Oliel N, Shevell M, Law M, Birnbaum $\mathrm{R}$, Rosenbaum P, et al. Play and be happy? Leisure participation and quality of life in school-aged children with cerebral palsy. Int J Pediatr. 2012;2012:387280. https://doi.org/10.1155/2012/387280

10. World Health Organization - WHO .T. W. B. World report on disability 2011. São Paulo: World Health Organization; 2011.

11. Teixeira-Machado L, Azevedo-Santos I, Desantana JM. Dance improves functionality and psychosocial adjustment in cerebral palsy: a randomized controlled clinical trial. Am J Phys Med Rehabil. 2017 Jun;96(6):424-9. https://doi.org/10.1097/PHM.0000000000000646.

12. López-Ortiz C, Egan T, Gaebler-Spira DJ. Pilot study of a targeted dance class for physical rehabilitation in children with cerebral palsy. SAGE Open Med. 2016 Sep;4:2050312116670926. https://doi.org/10.1177/2050312116670926

13. López-Ortiz C, Gladden K, Deon L, Schmidt J, Girolami G, GaeblerSpira D. Dance program for physical rehabilitation and participation in children with cerebral palsy. Arts Health. 2012 Feb;4(1):39-54. https://doi.org/10.1080/17533015.2011.564193

14. Rosenbaum PL, Walter SD, Hanna SE, Palisano RJ, Russell DJ, Raina $P$, et al. Prognosis for gross motor function in cerebral palsy: creation of motor development curves. JAMA. 2002 Sep;288(11):1357-63. https://doi.org/10.1001/jama.288.11.1357 
15. Lerman JA, Sullivan E, Barnes DA, Haynes RJ. The Pediatric Outcomes Data Collection Instrument (PODCl) and functional assessment of patients with unilateral upper extremity deficiencies. J Pediatr Orthop, J Pediatr Orthop. 2005 May-Jun;25(3):405-7. https://doi.org/10.1097/01.bpo.0000149866.80894.70

16. Bordin IA, Rocha MM, Paula CS, Teixeira MC, Achenbach TM, Rescorla LA, et al. Child Behavior Checklist (CBCL),Youth Self-Report (YSR) and Teacher's Report Form(TRF): an overview of the development of the original and Brazilian versions. Cad Saude Publica. 2013 Jan;29(1):13-28. https://doi.org/10.1590/S0102-311X2013000100004

17. Palisano RJ, Orlin M, Chiarello LA, Oeffinger D, Polansky M, Maggs J, et al. Determinants of intensity of participation in leisure and recreational activities by youth with cerebral palsy. Arch Phys Med Rehabil. 2011 Sep;92(9):1468-76. https://doi.org/10.1016/j.apmr.2011.04.007

18. Chen KL, Wang HY, Tseng MH, Shieh JY, Lu L, Yao KP, et al. The Cerebral Palsy Quality of Life for Children (CP QOL-Child): evidence of construct validity. Res Dev Disabil. 2013 Mar;34(3):994-1000. https://doi.org/10.1016/j.ridd.2012.11.025

19. Tsoi WS, Zhang LA, Wang WY, Tsang KL, Lo SK. Improving quality of life of children with cerebral palsy: a systematic review of clinical trials. Child Care Health Dev. 2012 Jan;38(1):21-31. https://doi.org/10.1111/j.1365-2214.2011.01255.x

20. Bjornson KF, Belza B, Kartin D, Logsdon R, McLaughlin J, Thompson EA. The relationship of physical activity to health status and quality of life in cerebral palsy. Pediatr Phys Ther. 2008;20(3):247-53. https://doi.org/10.1097/PEP.0b013e318181a959

21. Colver A, Rapp M, Eisemann N, Ehlinger $V$, Thyen U, Dickinson HO, et al. Self-reported quality of life of adolescents with cerebral palsy: a crosssectional and longitudinal analysis. Lancet. 2015 Feb;385(9969):70516. https://doi.org/10.1016/S0140-6736(14)61229-0

22. Coutinho dos Santos LH, Bufara Rodrigues DC, Simões de Assis TR, Bruck I. Effective results with botulinum toxin in cerebral palsy. Pediatr Neurol. 2011 May;44(5):357-63. https://doi.org/10.1016/j.pediatrneurol.2010.12.001

23. Herman J. Dance as art and therapy in cerebral palsy. Dev Med Child Neurol. 2019 Apr;61(4):386. https://doi.org/10.1111/dmcn.14151

24. Sato N, Nunome H, Ikegami Y. Kinematic analysis of basic rhythmic movements of hip-hop dance: motion characteristics common to expert dancers. J Appl Biomech. 2015 Feb;31(1):1-7. https://doi.org/10.1123/JAB.2014-0027

25. Reid LB, Pagnozzi AM, Fiori S, Boyd RN, Dowson N, Rose SE. Measuring neuroplasticity associated with cerebral palsy rehabilitation: an MRI based power analysis. Int J Dev Neurosci. 2017 May;58:17-25. https://doi.org/10.1016/j.ijdevneu.2017.01.010

26. Zonta MB, Bruck I, Puppi M, Muzzolon S, Neto AC, Coutinho dos Santos LH. Effects of early spasticity treatment on children with hemiplegic cerebral palsy: a preliminary study. Arq Neuropsiquiatr. 2013 Jul;71(7):453-61. https://doi.org/10.1590/0004-282X20130061

27. Verschuren O, Peterson MD, Balemans AC, Hurvitz EA. Exercise and physical activity recommendations for people with cerebral palsy. Dev Med Child Neurol. 2016 Aug;58(8):798-808. https://doi.org/10.1111/dmcn.13053

28. Granier F. Art-therapy. Ann Med Psychol (Paris). 2011;169(10):680-4. https://doi.org/10.1016/j.amp.2011.10.010

29. Murrock CJ, Graor CH. The effects of dance on depression, physical function, and disability in underserved adults. J Aging Phys Act. 2014 Jul;22(3):380-5. https://doi.org/10.1123/JAPA.2013-0003 •

30. Braüninger I. The efficacy of dance movement therapy group of improvement of quality of life: A randomized cotrolled trial. Arts Psychother. 2012;39(4):296-303. https://doi.org/10.1016/j.aip.2012.03.008.

31. Freilich $\mathrm{R}$, Shetchtman Z. The contribution of arte therapy to the social, emotional, and academic ajustment of children with learning disabilites. Art Psychother. 2010;37(2):97-105. https://doi.org/10.1016/j.aip.2010.02.003 


\section{ADAPTED HIP-HOP DANCE}

Hip-hop was chosen due to some characteristics associated with this type of dance that meet the motor needs of children/adolescents with cerebral palsy, including:

- Genre and repertoire: The songs of this dance genre are part of a musical context appreciated by children/adolescents, and the contact with gestures and melodic repertoire promotes better assimilation of choreographic sequences ${ }^{24}$. The vast repertoire of hip-hop steps can be adjusted, respecting individual physical conditions and capabilities.

- Rhythm: Well-marked rhythmic beats require the execution of defined body movements, usually augmenting or isolating some body parts. This demands from the dancer body awareness and trunk mobility ${ }^{24}$, preventing complications and deterioration of his or her health status ${ }^{27}$. Rhythmic alternation suggests that movements are executed repetitively, which benefits motor learning and reduces spasticity ${ }^{26}$. The movements of the trunk and lower and upper limbs can be trained separately to be executed simultaneously and continuously, in a coordinated way and synchronized with the rhythm ${ }^{24}$.

- Mobility: The training promotes dissociation of the pelvic and scapular waists, which is necessary to reduce fixed postures caused as a result of spasticity ${ }^{26}$. The movements carried out on the floor stimulate the weight transfer to hands and feet for body support ${ }^{24}$, necessary for appropriate bone development, neuromuscular stimulation, and muscle strengthening, as well as to reduce neglect of the affected limbs $^{26}$. Recommended shoes for this dance are sneakers with flat soles, which enable orthosis during the activity. The movements can be selected and adjusted to promote heel support and avoid plantar flexion. 